\title{
Hydrolytic Degradation of Thermoplastic Copolyester Nanocomposites
}

\author{
Eid M Alosime ${ }^{1 *}$ and Darren J Martin ${ }^{2}$ \\ ${ }^{1}$ National Centre for Irradiation Technology, King Abdulaziz City for Science and Technology, Saudi Arabia \\ ${ }^{2}$ Australian Institute for Bioengineering and Nanotechnology, The University of Queensland, Australia
}

Submission: November 15, 2018; Published: November 30, 2018

*Corresponding author: Eid Alosime, National Centre for Irradiation Technology, King Abdulaziz City for Science and Technology, P.0. Box 6086, Riyadh 11442, Saudi Arabia

\begin{abstract}
Thermoplastic copolyesters (TPE-Es) are multi-block copolymers commonly incorporating hard (polyester) and soft (polyether) blocks. Multifunctional epoxy-based chain extenders (TGDDM) are one of the additives that serve to reverse molecular weight (MW) damage caused by the process of hydrolysis of TPE-E. There are two functional groups that are capable of additional reactions on the terminal hydroxyl and carboxyl groups of TPE-E. Considering the hydrogen bonded hard segments in hard domains are less susceptible to hydrolysis compared to the non-hydrogen bonded equivalents, the phase separated morphology of polyether-polyester copolymers based TGDDM also provides to the longterm stability. The molecular weight of TPE-E was determined by GPC and the thermal and tensile behaviors were investigated.
\end{abstract}

Keywords: Thermoplastic copolyester; Crosslinking; Hydrolysis; Mechanical properties

Abbreviations: TPE-Es: Thermoplastic Copolyesters; MW: Molecular Weight; TGDDM: Tetraglycidyl-4,4-Diamino-Diphenylmethane;

\section{Introduction}

Polyester hydrolysis produces hydrophilic acid (carboxyl) end groups in the polymer, which increase the ability for the polymer to absorb water because of the decrease in its surface resistance and hydrophobicity [1-3].

Chain extenders remain necessary in improving the molecular weight of TPE-E and, consequently, broaden their industrial applications. Chain extenders help in the substitution of polyester hydrolysis-caused molecular weight damage, leading to the production of a polymer with desired melting strength and rheological properties. The chain extenders function effectively, predominantly due to their bi-functional groups that inherently react with polymer terminal groups. Moreover, specific chain extenders, such as tetraglycidyl-4,4-diamino-diphenylmethane (TGDDM), are vital in the enhancement of TPE-E molecular weights. Consequently, TPE-E would have improved rheological, mechanical, and thermal characteristics [4].

Hytrel ${ }^{\circledR} 3078$ is a brand of TPE-E (copolyesters, COPEs) under the trademark of DuPont. Hytrel 3078 nanocompsite prepared by reactive extrusion-based masterbatch (HC1-C2), dry feed (HC2) of organo-fluoromica combined with TGDDM, the postaddition of TGDDM (HC1-T) and the direct-addition of TGDDMorgano-fluoromica (HT-C1) were compared for their resistance to hydrolysis in aqueous buffer solutions for $140 \mathrm{~h}$ solution at $100^{\circ} \mathrm{C}$ at pH 1 (Figure 1).

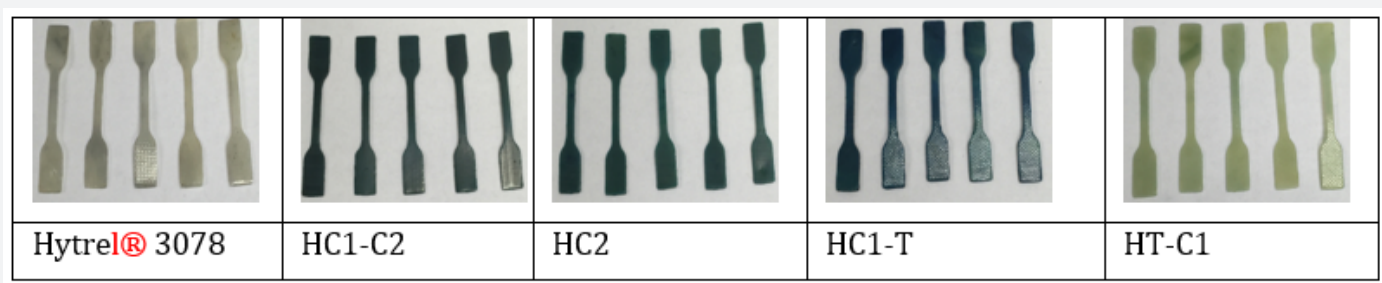

Figure 1: The hydrolysis experiments carried out by immersing dumbbell samples (5 replicates) in $\mathrm{pH} 1$ aqueous buffer solutions for $140 \mathrm{~h}$ at $100^{\circ} \mathrm{C}$.

The enlargement of the MWD for the nanocomposites can also be indicated by the polydispersity index $\left(\mathrm{PDI}=\mathrm{M}_{\mathrm{w}} / \mathrm{M}_{\mathrm{n}}\right)$, besides extremely high molecular weights above $2 \times 10^{6} \mathrm{~g} / \mathrm{mol}$ are also obtained. These outcomes show modifier chain extension efficiency which has an effect on the rheological characteristics of the material.

The PDI of the host polymer before and after reactive modification via different processing routes (blank TPE-E, HT-C1, 
HC2, HC1-C2 and HC1-T) are also given in Table 1. A significant decrease in $M_{n}$ of HC1-C2 nanocomposites occurred during a masterbatch of reactive nanofiller in TPE-E. It is still expected that there may be thermal and thermo-oxidative degradation processes associated with reactive processing this TPE-E, which are responsible for the molecular weight decrease in the melt compounded TPE-E. The relatively low $M_{w^{\prime}}$ suggesting that HC1-C2 is less crystalline than other modified nanocomposites, and therefore it was not possible to obtain high molecular weight TPE-E. Higher molecular weight may be obtained if the TGDDM is post-added with TPE-E matrix for HC1-T. It was shown that the $M_{n}$ of the HC1-T was twice that of first adding of TGDDM into TPE-E (HT-C1). This halving of molecular weight resulted in the HT-C1 having a tensile strength of $35 \mathrm{MPa}$, which was $4.9 \mathrm{MPa}$ lower than that of the HC1-T (39.9MPa) (Figure 2). The postaddition of TGDDM decreased the PDI of TPE-E nanocomposite.
This contrasts with the significant improvement in $\mathrm{M}_{w}$ of HC1-C2. The high PDI value can also be attributed to higher branching formation of TPE-E. Twin screw extrusion, which compounds thermally-sensitive materials, yields a far greater shear energy than single screw extrusion, which results in a loss of molecular weight and a decrease in properties and performance [5].

Table 1: Characteristic molecular weights obtained by GPC of TPE-E nanocomposites.

\begin{tabular}{|c|c|c|c|c|}
\hline Materials & $\mathbf{M}_{\mathbf{n}}$ & $\mathbf{M}_{\mathbf{w}}$ & $\mathbf{M}_{\mathbf{z}}$ & Polydispersity (PDI) \\
\hline Blank & 46,056 & 73,177 & 112,697 & 1.58 \\
\hline HT-C1 & 57,382 & 101,986 & 172,302 & 1.77 \\
\hline HC2 & 56,713 & 106,106 & 183,313 & 1.87 \\
\hline HC1-C2 & 38,947 & 72,522 & 127,113 & 1.86 \\
\hline HC1-T & 94,225 & 140,520 & 207,950 & 1.49 \\
\hline
\end{tabular}



Figure 2: Effect of modification route on the (a) modulus, and (b) stress-strain curve of TPE-E nanocomposites.
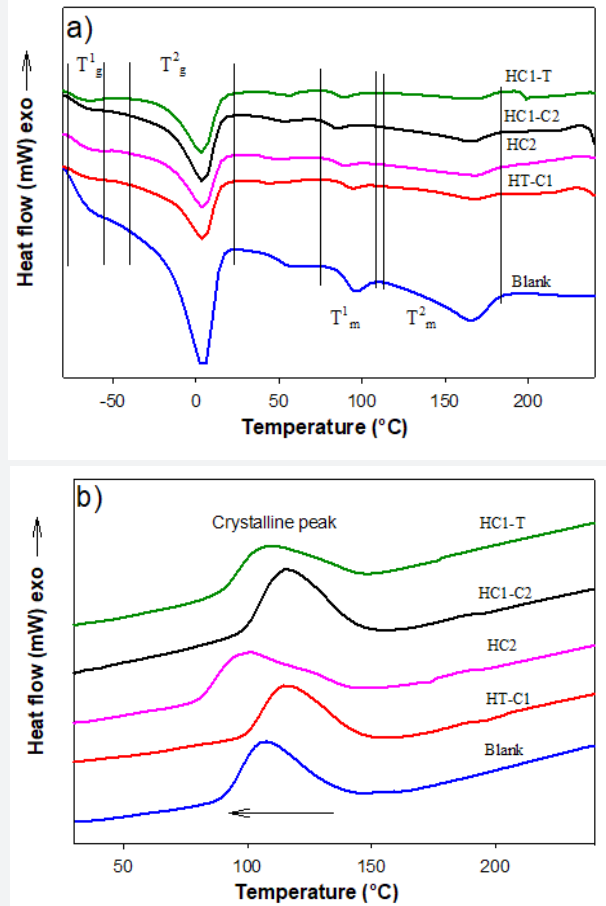

Figure 3: DSC thermograms of (a) heating scan and (b) cooling scan of of TPE-E nanocomposites. 
The thermal and mechanical properties of polymers are influenced by polydispersity of the hard segments. The presence of many epoxy groups gives rise to a highly crosslinked network within the nanocomposite. As seen in Figure 3, the addition of TGDDM in HT-C1, HC1-C2 and HC1-T clearly shifted the exothermic heat of crystallisation peaks of the hard segment to higher temperatures. The result of these studies indicates that hard segments of uniform length crystalise faster and better than hard segments of non-uniform length. However, the hard segments represent a physical cross-link which report elastomeric properties to the soft phase. The hard-soft segmental solubility parameters and aligned hard and soft segments, polydispersity and molecular weight, as well as the processing and thermal history of the TPE-E host matrix are essential factor to be considered to the tensile properties demonstrated by the nanocomposites [6].

This work is licensed under Creative Commons Attribution 4.0 License DOI: 10.19080/AJOP.2018.02.555581

\section{References}

1. Choi T, Weksler J, Padsalgikar A, Hernández R, Runt J (2009) Polydimethylsiloxane-Based Polyurethanes: Phase-Separated Morphology and In Vitro Oxidative Biostability. Aust J chem 62(8): 794-798.

2. Kelleher G, Bebbington H, Falcone R, Ryan T, Went P (1979) Soc Plast Eng Tech Papers 25: 527.

3. Amin M, Akbar M, Amin S (2007) Hydrophobicity of Silicone Rubber used for Outdoor Insulation (An Overview). Rev Adv Mater Sci 16: 1026.

4. Roh JH, Kim D, Lee HD, Yoon BK (2012) Preparation of high molecular weight and elastic copolyester by reactive extrusion with diisocyanate compound for laser printing process. J Polym. Eng 32(3): 207-214.

5. Dennis HR, Hunter DL, Chang D, Kim S, White JL, et al. (2001) Effect of melt processing conditions on the extent of exfoliation in organoclaybased nanocomposites. Polymer 42(23): 9513-9522.

6. Miller JA, Lin SB, Hwang KK, Wu KS, Gibson PE, et al. (1985) Properties of polyether-polyurethane block copolymers: effects of hard segment length distribution. Macromolecules 18(1): 32-44.

\section{Your next submission with Juniper Publishers will reach you the below assets}

- Quality Editorial service

- Swift Peer Review

- Reprints availability

- E-prints Service

- Manuscript Podcast for convenient understanding

- Global attainment for your research

- Manuscript accessibility in different formats

( Pdf, E-pub, Full Text, Audio)

- Unceasing customer service

Track the below URL for one-step submission

https://juniperpublishers.com/online-submission.php 